\title{
A EXPANSÃo DO ENSINO SECUNDÁRIO NO BRASIL PÓS-1930
}

\author{
LA EXPANSIÓN DE LA EDUCACIÓN SECUNDARIA EN BRASIL POST-1930
}

THE EXPANSION OF SECONDARY EDUCATION IN BRAZIL POST-1930

\author{
Jussara Cassiano NASCIMENTO ${ }^{1}$ \\ Lia Ciomar Macedo de FARIA ${ }^{2}$
}

\begin{abstract}
RESUMO: Recompomos neste artigo perspectivas históricas voltadas para a expansão do ensino secundário no Brasil pós 1930. Nunes (1999) informa que essa expansão se ampliou após o colapso econômico das instituições, motivado pela quebra da bolsa de valores de Nova York, catástrofe de repercussão mundial que, dentre outras consequências, tornou visível a necessidade de reestruturação da educação secundária até então oferecida, já que não comportava mais um ensino formalista, voltado para formação de uma elite que vislumbrava o ensino superior. A base teórica e metodológica aborda os trabalhos de Silva (1969), Abreu (1955), Palma Filho (2005) e Nunes (1999). Teremos olhar atento para o ensino secundário desenvolvido no Rio de Janeiro, onde detectamos que essa oferta não se limitou a estabelecimentos públicos de ensino.
\end{abstract}

PALAVRAS-CHAVE: História da educação. Expansão do ensino secundário. Instituições educacionais.

RESUMEN: En este articulo recomponemos perspectivas históricas encaminadas a la expansión de la educación secundaria en Brasil después de 1930. Nunes (1999), informa que esta expansión se expandió luego del colapso económico de las instituciones, motivado por el colapso de la bolsa de valores de Nueva York; catástrofe de repercusión mundial que, visibilizó la necesidad de reestructurar la educación secundaria que hasta ese momento se ofrecía, ya que ya no incluía la educación formal, a formar una élite que contemplara la educación superior. La base teórica y metodológica aborda Silva (1969), Abreu (1955), Palma Filho (2005) y Nunes (1999). Veremos de cerca la educación secundaria, en Río de Janeiro, donde descubrimos que esta oferta no se limitaba a las escuelas públicas.

PALABRAS CLAVE: Historia de la Educación. Expansión de la enseñanza secundaria. Instituciones educativas.

ABSTRACT: In this article, we recompose historical perspectives aimed at expanding secondary education in Brazil after 1930. Nunes (1999), informs that this expansion

\footnotetext{
${ }^{1}$ Colégio Brigadeiro Newton Braga (CBNB), Rio de Janeiro - RJ - Brasil. Assessora Pedagógica da Diretoria e Professora do Ensino Básico Técnico e Tecnológico do Departamento de Educação - Força Aérea Brasileira (FAB). Pós-Doutorado em Educação (UERJ). ORCID: https://orcid.org/0000-0003-0153-4103. E-mail: professorajussara@yahoo.com.br

${ }^{2}$ Universidade do Estado do Rio de Janeiro (UERJ), Rio de Janeiro - RJ - Brasil. Professora Titular do Departamento de Educação. Doutorado em Educação (UFRJ). ORCID: https://orcid.org/0000-0002-9172-9934. E-mail: liafolia11@gmail.com
} 
expanded after the economic collapse of the institutions, motivated by the crash of the New York stock exchange; catastrophe of worldwide repercussion that, among other consequences, made visible the need to restructure the secondary education hitherto offered since it no longer included formal education, aimed at forming an elite that envisioned higher education. The theoretical and methodological basis addresses the works of Silva (1969), Abreu (1955), Palma Filho (2005) and Nunes (1999). We will have a close look at secondary education, developed in Rio de Janeiro, where we found that this offer was not limited to public schools.

KEYWORDS: History of Education. Expansion of secondary education. Educational Institutions.

\section{Introdução}

Maria Thétis Nunes (1999), na obra Ensino Secundário e Sociedade Brasileira, analisa que, a partir de 1930, houve um colapso das instituições políticas tradicionais, tendo início uma nova etapa na vida política brasileira. Essa crise esteve relacionada ao advento da quebra da bolsa de Nova York, de repercussão mundial, que se refletiu de forma desastrosa em nossa economia, causando consequências como a queda do preço do café, a descida da taxa cambial e a quebra do volume das exportações, dentre outras. Tal contexto contribuiu para a desigualdade social brasileira, revelando o proletariado e os setores produtivos da classe média de um lado e a burguesia e o latifúndio mercantil do outro, dando início ao desenvolvimento de um novo Brasil.

O que se observa é que essas mudanças tornaram visível o fato de que a educação secundária até então oferecida era incompatível com a nova realidade do país, que já não comportava mais um tipo de ensino formalista e arcaico, visando a formação de uma elite para o ensino superior (FIALHO; SÁ, 2018).

A fundação da Associação Brasileira de Educação (ABE), em 1924, reunindo personalidades ilustres e cultas, sob a liderança do professor Heitor Lyra da Silva, e o posterior crescimento do movimento, incorporando intelectuais nos anos subsequentes, acabara por influenciar a elaboração de leis que serviram de diretrizes e bases para a educação brasileira, como consequência das inúmeras conferências e congressos educacionais realizados, principalmente nos estados de São Paulo, Minas Gerais e no próprio Distrito Federal, onde os educadores analisavam a política educacional vigente. 
Assim, várias transformações aconteceram a partir da Revolução de $1930^{3}$, exigindo um sistema educacional público para aquela nova realidade brasileira. Dessa forma, surgiu a necessidade de criação de novos órgãos administrativos, entre eles o Ministério da Educação e Saúde, criado pelo Decreto-lei n. 19.402, de 14 de novembro de 1930, cujo primeiro ocupante foi o Ministro Francisco Campos.

\section{A reforma Francisco Campos e a expansão do ensino secundário}

Em se tratando da realidade educacional dos anos 1930 e contrariando a proposta de um sistema único de ensino, articulado em diversos níveis, o Ministro da Educação Francisco Campos, em 1931, apresentou uma proposta diferente que se direcionava com mais força aos níveis do ensino pós-primário, como o secundário, o comercial e o superior.

A reforma foi imposta a todo o território nacional. De acordo com as ideias de Francisco Campos, estava alicerçada a crença de que era possível reformar a sociedade com a melhoria da escola e da formação das pessoas, modernizando as elites. Entretanto, o ensino secundário foi reformado com uma lógica de formação propedêutica voltada para o ensino superior. A partir dos cursos técnicos profissionais, foi organizado o ensino comercial voltado para o mercado de trabalho, que não garantia ao estudante cursar o ensino superior, privilégio exclusivo dos estudantes que concluíam o ensino secundário propedêutico. Nesse período, foi instituído o sistema universitário no Brasil e a organização da Universidade do Brasil (1937), no Rio de Janeiro. Assim, a Reforma Francisco Campos estabeleceu um projeto que apontava para dois modelos de educação: um voltado para o pensar e outro para o produzir ${ }^{4}$.

Ao propor a reorganização do ensino secundário e comercial, a Reforma Francisco Campos organizou esses dois cursos de forma totalmente independente, ganhando organicidade e adotando um currículo seriado. O tempo de duração desses cursos passou a ser o fundamental, em cinco anos, e o complementar, em dois anos.

A organização curricular apresentava, de forma mais integrada, as disciplinas de humanidades e as científicas; e o ciclo complementar foi estruturado como propedêutico,

\footnotetext{
${ }^{3}$ A Revolução de 1930 foi um movimento armado, liderado pelos estados do Rio Grande do Sul, Minas Gerais e Paraíba, devido à insatisfação com o resultado das eleições presidenciais, que resultou em um golpe de Estado: o Golpe de 1930. Esse Golpe derrubou o então Presidente da República, Washington Luís, em 24 de outubro de 1930, e impediu a posse do presidente eleito, Júlio Prestes, colocando fim à República Velha.

${ }^{4}$ A educação para $o$ pensar era destinada àqueles que deveriam orientar e definir as grandes decisões coletivas e estabelecer a organização política que viria dar sentido e direção à economia nacional. A educação para produzir era destinada à formação daqueles que deveriam atender as necessidades do mercado. Era esse o objetivo da reforma do ensino comercial, transformando-o em vários cursos técnicos, mas que não davam acesso ao ensino superior (MORAES, 2000).
} 
subdividindo-se em categorias diferentes para estudos pré-jurídicos, pré-médicos e prépolitécnicos, com o objetivo de preparar o estudante para o ensino superior.

A Reforma Francisco Campos também organizou o ensino comercial em dois ciclos: o primeiro era o curso propedêutico de três anos e o curso auxiliar de comércio em dois anos. $\mathrm{O}$ segundo ciclo tinha cinco modalidades: curso de perito contador (três anos), curso técnico de secretariado (um ano), curso de guarda-livros (dois anos), curso de administrador-vendedor (dois anos) e curso de atuário (três anos). Somente os cursos de perito contador e atuário davam acesso ao ensino superior, mas só para o curso superior de finanças. Ou seja, o aluno que cursava o ensino médio profissional ficava impossibilitado de acessar outro curso posterior.

Para Demerval Saviani (2013), essa proposta de ensino secundário revelava caráter elitista, na medida em que unia a um currículo enciclopédico uma proposta extremamente rígida de avaliação, mantendo a função tradicional do ensino secundário, cujo objetivo era a preparação para o ensino superior.

Naquele momento, estava sendo elaborada uma nova Constituição, e os debates ocorridos na Assembleia Constituinte de 1933 e 1934 tinham como propósito estabelecer um capítulo sobre a educação para todo o país. Dentre os participantes desses debates destacavam-se os educadores liberais e os intelectuais católicos.

Os educadores liberais ${ }^{5}$, desde os anos de 1920, estavam influenciados pelo movimento de renovação pedagógica chamado de escolanovismo e queriam difundir essas novas perspectivas para o campo da educação. Dentre os pontos que defendiam estavam a institucionalização e a expansão da escola pública, além da laicidade do ensino e a renovação dos métodos pedagógicos. Já os intelectuais católicos defendiam os interesses de uma escola confessional que, durante muito tempo, exerceu o controle do ensino, usando métodos tradicionais e a educação religiosa nas escolas públicas (FIALHO; SOUSA, 2021).

A questão educacional entre os liberais e os católicos tornou-se tão polêmica que, no ano de 1932, os líderes do movimento renovador lançaram o Manifesto dos Pioneiros da Educação Nova, assinado pelos mais eminentes educadores nacionais, tornando públicos os princípios fundamentais que os renovadores defendiam, procurando adaptar a educação às transformações que se processavam no país.

\footnotetext{
${ }^{5}$ Os educadores liberais envolveram-se em um movimento caracterizado por novas ideias pedagógicas que estavam em pauta nos EUA e Europa, com vistas à adequação do ensino na fase de desenvolvimento capitalista industrial. John Dewey foi um dos precursores dessas ideias, que envolviam a expansão das oportunidades escolares, como também novos métodos pedagógicos, em contraposição à escola tradicional.
} 
O Manifesto propunha um sistema de ensino articulado, abandonando o dualismo que existia, onde os ensinos primário e profissional destinavam-se aos pobres e o secundário e superior, aos ricos. Segundo Palma Filho (2005), esse Manifesto não é apenas um documento preocupado em estabelecer um diagnóstico do quadro educacional brasileiro, porque nele existe uma proposta de criação de um sistema de educação, ainda que seja um esboço geral no qual será inserido um programa educacional.

O Manifesto preconizava que o ensino secundário deveria ser organizado em dois ciclos, o primeiro tendo uma base comum, com duração de três anos, e o segundo, duas sessões: uma que desenvolveria o ensino das humanidades e a outra, a formação técnica. Mesmo propondo a unificação do ensino secundário, havia no Manifesto uma seção de caráter intelectual (ensino das humanidades e ciências) e outra de caráter manual (de formação técnica) que atenderia a força de trabalho.

O texto constitucional promulgado em 1934 atendeu algumas das reivindicações dos chamados pioneiros da educação, afirmando ser a educação um direito de todos e dever do Estado, cabendo a este procurar proporcioná-la, estabelecendo a obrigatoriedade da escola primária integral e determinando a gratuidade do ensino para esse nível. O texto admite também a necessidade de um Plano Nacional de Educação que pudesse coordenar as atividades de ensino em todos os níveis.

No entanto, os católicos conseguiram que o ensino religioso fosse facultativo nas escolas oficiais, questão que já havia sido superada pela Constituição do Estado do Rio de Janeiro, de 1931.

\section{As reformas educacionais nos anos 1940/50}

Cunha (1983) analisa que o Estado, no período ditatorial de Vargas, ao assumir um projeto de desenvolvimento industrial para o país, reforça a sua preocupação em qualificar a força de trabalho. Dessa forma, entre os anos de 1942 e 1946 ocorrem reformas educacionais para o ensino primário e médio, através das Leis Orgânicas.

A partir do ano de 1942, o Ministro da Educação Gustavo Capanema dá início à publicação de vários decretos-lei. Quatro decretos são editados durante o Estado Novo: a) Decreto-lei 4.073, em 30 de janeiro de 1942 (Lei Orgânica do Ensino Industrial); b) Decreto-lei 4.048, em 22 de janeiro de 1942, cria o Serviço Nacional de Aprendizagem Industrial (SENAI), c) Decreto-lei 4.244, em 9 de abril de 1942 (Lei Orgânica do Ensino Secundário); e d) Decreto-lei 6.141, em 28 de dezembro de 1943 (Lei Orgânica do Ensino Comercial). Após o golpe militar que derrubou Vargas 
(1945), durante o Governo Provisório presidido pelo Presidente do Supremo Tribunal Federal (STF), foram publicados mais quatro decretos-lei: a) Decreto-lei 8.529, em 02 de janeiro de 1946 (Lei Orgânica do Ensino Primário); b) Decreto-lei 8.530, em 02 de janeiro de 1946 (Lei Orgânica do Ensino Normal); c) Decreto-lei 8.621 e 8.622, em 10 de janeiro de 1946, criam o Serviço Nacional de Aprendizagem Comercial (SENAC) e d) Decreto-lei 9.613, em 20 de agosto de 1946, Lei Orgânica do Ensino Agrícola (PALMA FILHO, 2005, p. 11).

Nesse contexto, o Ministro Capanema, que sucedeu a Francisco Campos, propôs que uma parte do ensino médio fosse organizado como preparação para o trabalho. Assim, o ensino médio industrial, comercial ou agrícola se voltaria exclusivamente para a formação do jovem trabalhador.

A primeira Lei Orgânica do Ensino Industrial, promulgada em 1942, organizou esse ensino em dois ciclos: o primeiro formado por cursos técnicos de três a quatro anos e um curso pedagógico de um ano; e o segundo, um curso industrial básico de quatro anos e mais um curso de mestria de dois anos. Além desses cursos, a lei previa também cursos artesanais, de duração reduzida, que ensinava ofícios.

O Decreto-Lei n. 6.141, de 28 de dezembro de 1943, definiu o ensino comercial em todo o país e foi denominado Lei Orgânica do Ensino Comercial, propondo que os cursos fossem estruturados em dois ciclos, ampliando o seu tempo de duração e incorporando seis cursos técnicos: secretariado, comércio, administração, propaganda, contabilidade e estatística.

Paralelamente a essa modalidade de ensino técnico profissional, foi proposto o Decreto-lei n. 9.613, de 20 de agosto de 1946, também estruturado em dois ciclos: o primeiro com duração de quatro anos e mais o curso de mestria de dois anos; e o segundo com cursos técnicos de três anos, mais dois anos de magistério, além do curso de ensino agrícola de um ano.

Além das reformas para a educação técnico-profissional, a Reforma Capanema definiu uma reorganização do ensino secundário, determinando que a finalidade da escola secundária fosse a de formar as individualidades condutoras do país. Como já previsto pela Reforma Francisco Campos, a nova lei também estabeleceu um primeiro ciclo, chamado ginasial, de quatro anos; e um segundo ciclo, dividido em dois cursos de três anos: o clássico e o científico. $\mathrm{O}$ curso clássico dava maior ênfase às humanidades, e o científico, às ciências naturais, o que reafirmava o caráter de cultura geral e humanista nos currículos.

Nunes (1980) esclarece que a reorganização do ensino médio na década de 1940, através das Leis Orgânicas, não foi adequada e suficiente para atender às exigências do 
capitalismo industrial vigente, surgindo um sistema escolar paralelo, resultando na criação do Serviço Nacional da Indústria (SENAI), Serviço Nacional do Comércio (SENAC) e das Escolas Técnicas Federais.

Esses cursos nasceram da necessidade e urgência das indústrias em promover qualificação profissional mínima para os operários, pois o sistema regular de ensino estabelecido pelas Leis Orgânicas não oferecia as condições necessárias de adaptação do ensino às transformações da economia e, consequentemente, não atendia à demanda de mão de obra qualificada exigida pelo novo mercado de trabalho (NASCIMENTO; MACHADO; ALMEIDA, 2020). O SENAI e o SENAC, cada qual na sua especificidade, passaram a ser responsáveis pela oferta de cursos técnicos de curta duração, enquanto o sistema oficial passou a ocupar-se preferencialmente pelos cursos de formação plena.

A partir da Constituição de 1937 e da promulgação das Leis Orgânicas do Ensino, o Estado brasileiro foi marcado por uma dualidade na organização do ensino, desvelando as diferenças sociais. Por um lado, o ensino secundário e superior visou à elite, enquanto, por outro lado, o ensino primário e profissional, às classes populares, assim definindo um ensino secundário propedêutico elitizado para os primeiros, e o profissional como curso terminal para filhos dos trabalhadores, em consonância com os interesses do mercado.

No contexto de 1948, os educadores liberais apresentaram um anteprojeto de Lei de Diretrizes e Bases para a Educação Nacional, encaminhado pelo Ministro Clemente Mariani à Câmara dos Deputados, propondo a obrigatoriedade e a gratuidade do ensino primário e a ampliação progressiva da gratuidade para os demais níveis de ensino.

O anteprojeto apresentado em 1948 não determinava o fim da dualidade no ensino médio brasileiro, mas previa mudanças que iriam valorizar os cursos profissionais. A primeira mudança dizia respeito à inserção de quatro disciplinas do ginásio secundário no 1. ciclo e cinco disciplinas de caráter cultural no 2. ciclo. Por sua vez, a segunda mudança permitia criar uma ligação entre os ensinos secundário e profissional, cujo objetivo era acabar com a distância que havia entre esses dois cursos.

$\mathrm{Na}$ segunda metade dos anos de 1940, a oferta educacional ainda atendia, de forma restrita, à sociedade. Menos da metade da população escolar tinha acesso à escola elementar, e, para uma minoria que chegava ao ensino pós-primário, ficava aberta apenas a possibilidade de cursar uma das modalidades do ensino profissional. $\mathrm{O}$ ensino secundário, que daria promoção aos cursos superiores, ainda era negado à maioria do povo brasileiro.

Para Cunha (1991), essa dificuldade de acesso à escola secundária dava-se pelo seu caráter elitista, além do número reduzido de escolas públicas que o ofereciam. Assim, 
perpetuava-se a separação do ensino pós-primário entre os ramos secundário e profíssional. Ademais, havia poucos ginásios públicos, o que favorecia o predomínio de escolas secundárias privadas que, segundo Silva (1969), no início dos anos de 1940, totalizavam $73,3 \%$ das matrículas referentes ao ensino secundário do país.

A respeito, Beisiegel (1986) ressalta que, enquanto alguns administradores e educadores consideravam que a escola secundária era o encaminhamento escolar das futuras elites do país, amplos segmentos da população reagiam em busca da ampliação de oferta do número de vagas e lutavam para que seus filhos também tivessem acesso à escola secundária.

\title{
Ensino Secundário Pós-1930 em território fluminense
}

Em território fluminense, até a Primeira República ${ }^{6}$, predominava a escola particular que oferecia ensino elementar e médio para uma clientela oriunda da aristocracia rural $^{7}$ proveniente do Império, mas que ainda continuou, por um bom tempo, no controle político durante o período republicano. O poder público estadual, naquele período, limitava-se praticamente à instalação de poucas escolas públicas que funcionavam em prédios alugados, em sua maioria.

Tal cenário começou a se modificar nas décadas seguintes ao fim da República Velha, como nos aponta Abreu (1955, p. 211):

\begin{abstract}
A escola elementar como escola popular, escola para todos, para os filhos do povo, começa a aparecer e a se expandir, pelo território fluminense, somente nessas três ou quatro décadas [1930, 1940, 1950], quando se percebe maior esforço do poder público em propiciá-la à população em idade escolar. Por isso, teve inicialmente maior ênfase, a escola paga, mantida por particulares e que ministrava educação elementar e média a uma clientela privilegiada pelo poderio econômico.
\end{abstract}

A crise do setor agrário fluminense tornou-se aguda nas décadas de 1930, 1940 e 1950, acabando por conduzir ao esvaziamento das áreas rurais, acelerando o êxodo rural e

\footnotetext{
${ }^{6}$ A Primeira República Brasileira, normalmente chamada de República Velha, foi o período da história do Brasil que se estendeu da proclamação da República, em 15 de novembro de 1889, até a Revolução de 1930, e que depôs o Presidente Washington Luís. Nesse período, o Brasil foi nomeado Estados Unidos do Brasil, o mesmo nome usado na Constituição de 1891. A República Velha é dividida pelos historiadores em dois períodos. O primeiro período, chamado de República da Espada, por ser a República dos setores mobilizados pelo Exército e apoiados pelos republicanos, compreende da Proclamação da República do Brasil, em 15 de novembro de 1889, até a eleição do primeiro presidente civil, Prudente de Moraes. O segundo período ficou conhecido como República Oligárquica e se estende de 1894 até a Revolução de 1930. Caracterizou-se por dar maior poder para as elites regionais, em especial do sul e sudeste do país.

${ }^{7}$ Aristocracia significa os melhores, em sentido social, poder dos melhores, é uma forma de governo em que o poder político é dominado por um grupo elitista. Normalmente, as pessoas desse grupo são da classe dominante, da nobreza, tal como seu significado, como grandes proprietários de terra, militares, sacerdotes, etc.
} 
consequentemente o processo de urbanização, o que repercutiu sobre as transformações que aconteceram no sistema educacional público fluminense. Esse processo de migração rural atrelado ao crescimento natural da população fez avançar o processo de urbanização que se observou nos municípios da Baixada Fluminense. Brandão (1992) informa que no ano de 1950 já havia algum equilíbrio entre a população rural $(52,5 \%)$ e a população urbana do subúrbio (47,5\%). Porém, no ano de 1960 , a população urbana atingiu $61 \%$, enquanto a rural caiu para $39 \%$.

Nesse contexto de mudanças sociais ocorridas em regiões mais urbanizadas no estado do Rio de Janeiro, a educação escolar passou a ser reivindicada por parcelas cada vez mais amplas da sociedade fluminense, deixando de ser direcionada apenas para as classes mais abastadas. Abreu (1955) analisa que o povo começou a sentir, cada vez mais, a necessidade dessa escola, reconhecendo seu valor e importância e exigindo obrigações do Estado, maiores e mais onerosas, como o poder político juridicamente organizado.

A partir dos anos de 1940 e 1950, verificou-se um aumento significativo na rede pública estadual de ensino primário. As prefeituras dos municípios mais urbanizados contribuíram de forma mais efetiva com a oferta de ensino elementar, ampliando a oportunidade de acesso do povo à escola pública (LOPES, 2019).

Porém, de acordo com Bezerra (1995), enquanto se expandia o número de escolas primárias financiadas pelo governo, a quantidade de ginásios públicos apresentava um crescimento mínimo, não chegando a determinar uma ação mais efetiva por parte do Estado para aumentar o número de ginásios estaduais. Como consequência, houve expansão da rede privada de ensino nesse segmento.

A rede particular continuava se expandindo e o ensino primário fluminense tornou-se obrigatório para todas as crianças em idade escolar, através da Constituição Estadual de 1947, devendo ser ministrado pelo poder público. O texto dessa Constituição, em seu Art. 13, definia que o ensino público e primário estadual deveria ser gratuito, além de estabelecer, em seu Art. 142, que $20 \%$ da arrecadação dos impostos deveria ser destinada para a manutenção e desenvolvimento do ensino. 
O governo de Amaral Peixoto ${ }^{8}$ (1950-1954) objetivou ampliar ainda mais a oferta de ensino primário no antigo estado do Rio e continuou trabalhando na construção de prédios escolares, empreendimento já iniciado em sua administração anterior (1937-1945). Segundo dados oficiais apresentados pelo secretário de educação José de Moura e Silva, o aumento no número de grupos escolares foi expressivo e, ao final desse segundo governo Amaral Peixoto, já havia 62 grupos escolares prontos e dezenove em construção no estado do Rio de Janeiro.

O poder público estadual, além de utilizar recursos próprios, também contava com o auxílio financeiro do governo federal, obtidos através do Fundo Nacional de Ensino Primário (FNEP), cujos recursos destinavam-se à construção de escolas e grupos escolares nas áreas rurais. De acordo com os relatórios do secretário de educação José de Moura e Silva, apenas no ano de 1951 foram fundadas, no estado do Rio de Janeiro, 51 escolas em prédios construídos com recursos do FNEP.

Brandão (1992) analisa que o esvaziamento da população das regiões rurais do estado e o aumento da população nos centros urbanos marcam as políticas implementadas por Amaral Peixoto, que não se restringiam somente aos municípios de maior peso econômico. As verbas públicas destinadas ao saneamento urbano, transporte, eletrificação e construção de prédios escolares eram utilizadas de forma indistinta, pois atendiam áreas mais desenvolvidas ou mais atrasadas do estado.

As políticas adotadas por essa administração marcam o campo educacional, assinalando a preocupação do governo em atender tanto a população que vivia nos centros urbanos quanto a que vivia em área rural. Além da construção de novas unidades escolares, o governo criou mecanismos que estimularam a continuação do professorado em áreas rurais, impedindo a evasão do magistério nessas regiões. Uma medida importante foi a criação da primeira Escola Normal, no município de Cantagalo, em 27 de julho de 1952.

Em se tratando do aspecto de interiorização, o governo estadual, além de dar atendimento às populações que habitavam os centros urbanos, também se preocupou com as

${ }^{8}$ Ernâni do Amaral Peixoto nasceu em Niterói, em julho de 1905. Filho de Augusto do Amaral Peixoto e Alice Monteiro, cursou o secundário no Colégio Anchieta, da cidade de Nova Friburgo. Ingressou na Escola Naval em 1923. Em 1927 formou-se engenheiro geógrafo pela Escola Politécnica do Rio de Janeiro. Por influência do irmão, o também militar Augusto do Amaral Peixoto, teve contato com o movimento tenentista antes da Revolução de 1930, que apoiaria e alçaria Getúlio Vargas ao poder. No ano de 1937, após a instauração do Estado Novo, foi nomeado para o cargo de interventor federal no estado do Rio de Janeiro, procurando, junto a Getúlio Vargas, do qual se tornou genro em 1939, melhorias nas condições econômicas fluminenses, do que resultou a implantação da Companhia Siderúrgica Nacional (CSN), na cidade de Volta Redonda, e da Fábrica Nacional de Motores (FNM), em Duque de Caxias. No ano de 1951, assumiu seu segundo mandato, agora como governador eleito do estado do Rio de Janeiro, demonstrando logo no início do seu governo uma preocupação com a recuperação da economia do Estado, principalmente no que tange à ampliação do parque industrial fluminense. Desenvolveu um projeto denominado "Missões educativas rurais" que tinha como objetivo realizar um trabalho educativo e cultural junto à população rural do estado do Rio de Janeiro. Criou a escola normal de Cantagalo, em 1952, cujo objetivo era formar professores primários para atuar nas escolas em zonas rurais. 
áreas rurais e, ao longo dos anos de 1940 e primeira metade dos anos de 1950, as administrações estaduais se empenharam no sentido de ampliar a rede de ensino primário estadual por todo o território fluminense. Abaixo o quadro apresenta o crescimento de matrículas referentes ao ensino primário estadual em todas as regiões do estado do Rio de Janeiro.

De 1955 a 1958, a política educacional adotada pelo governo de Miguel Couto Filho ${ }^{9}$ também concentrou seus esforços na escola elementar, sendo instaladas mais 178 novas escolas, criados dezoito grupos escolares e oito jardins de infância. Além desse crescimento que se processou na rede primária estadual, as prefeituras fluminenses também ampliaram o número de estabelecimentos primários, durante os anos de 1950.

Ao longo dos anos de 1940 e 1950, a política de expansão aconteceu de forma decisiva para o ensino elementar, porém o mesmo não aconteceu com o ensino secundário, cuja oferta de matrículas na rede pública permaneceu limitada ao longo desses anos (FIALHO; FREIRE, 2018). A Constituição Estadual de 1947 anunciava a obrigatoriedade e gratuidade do ensino elementar, mas isso não estava previsto com relação ao ensino secundário (BEZERRA, 1995).

A oferta de ensino secundário acabou sendo reduzida e a quantidade de estabelecimentos que ofereciam alguma modalidade deste ensino à população era bem pequena. Com relação ao curso técnico profissional, o poder público estadual mantinha três escolas voltadas para o ensino industrial: a escola industrial Aurelino Leal, em Niterói, e a escola Nilo Peçanha, em Campos, voltadas à clientela feminina; e a Escola Industrial Henrique Lage, localizada também em Niterói, para o público masculino.

O relatório apresentado no ano de 1949 pelo diretor do Serviço de Estatística e Pesquisas Educacionais (SEPE) informa que, quanto ao ensino secundário, somente eram financiados pelo estado o Liceu Nilo Peçanha, em Niterói; o Liceu Humanidades, em Campos; e o Ginásio Estadual de Petrópolis. Anexos a esses dois liceus funcionavam o Instituto de Educação de Niterói e o Instituto de Educação de Campos.

Com o aumento de oportunidades de ingresso na escola pública primária oficial, a procura pelos outros níveis de ensino aumentou, principalmente nas regiões mais urbanizadas

\footnotetext{
${ }^{9}$ Miguel Couto Filho nasceu em 8 de maio de 1900, no Rio de Janeiro. No anos de 1930, entrou para a política, tendo sido eleito deputado estadual pelo Rio de Janeiro em 1934. Exerceu o mandato de 1935 a 1937, quando o Congresso foi fechado pelo golpe do Estado Novo. Com a redemocratização, foi eleito deputado federal constituinte pelo Partido Social Democrático (PSD). Em outubro de 1954, concorreu ao governo estadual do Rio de Janeiro pelo PSD e foi eleito. Renunciou em julho de 1958 para concorrer ao Senado Federal, para o qual foi eleito em outubro. Após a eleição, trocou o PSD pelo Partido Social Progressista (PSP), tornando-se líder do partido no Senado entre 1963 e 1965. Com o golpe militar de 1964 e a cassação do registro dos partidos pelo AI2, entrou para a Aliança Renovadora Nacional (ARENA), partido que apoiava o regime. Em 1966, conquistou novo mandato de deputado federal pelo estado do Rio por essa sigla. Morreu no exercício do mandato, em 2 de maio de 1969, enquanto viajava a Guarapari, balneário do Espírito Santo.
} 
do estado, fazendo com que a população sentisse necessidade de continuidade dos seus estudos. Assim, ampliou-se também a oferta de ensino médio em estabelecimentos particulares (BEZERRA, 1995).

Portanto, enquanto estado e município concentravam suas iniciativas educacionais voltadas para o ensino primário, o ensino secundário fluminense estava entregue à iniciativa privada. Segundo dados revelados por Abreu (1955), do total destinado aos gastos com o ensino, $75 \%$ estavam destinados ao ensino primário, $24,5 \%$ ao ensino secundário e $0,55 \%$ à escola superior.

De acordo com o relatório do secretário de educação José Moura e Silva, apresentado ao governador Amaral Peixoto, no ano de 1951, havia 2045 alunos matriculados no ensino secundário estadual, sendo 551 no curso ginasial e 435 no curso colegial do Liceu Nilo Peçanha; 614 no curso ginasial e 280 no curso colegial do Liceu de Humanidades de Campos; e 165 no ginásio estadual de Petrópolis.

Em se tratando da adoção de uma política voltada para a expansão da rede elementar de ensino, o governo de Amaral Peixoto alegou falta de recursos financeiros para efetivar sua implementação.

É altamente oneroso para o Governo criar e manter Ginásios ou Colégios. Enquanto são pequenos os recursos do Estado, melhor será que se concedam bolsas de estudo a jovens pobres e capazes, principalmente os que concluem o curso primário em grupos escolares estaduais, matriculando-os em estabelecimentos particulares (Relatório apresentado pelo Secretário José de Moura e Silva ao Governador Amaral Peixoto, 1951, p. 24).

Apesar dessa alegação de dificuldades financeiras, o governo não ficou totalmente alheio às reivindicações de ampliação dos ginásios públicos e seu secretário de educação propôs que fosse ampliado o número de matrículas nos estabelecimentos já existentes.

O grande interesse do público na procura do ensino secundário mantido pelo Estado nos dois Liceus de Humanidades, de Campos e Niterói, está a exigir do poder público maior atenção, no sentido de ampliar, ao menos nessas duas cidades, as suas possibilidades de atender ao maior número de jovens, notadamente os adolescentes dos bairros operários (Relatório apresentado pelo Secretário de Educação José de Moura e Silva ao Governador Amaral Peixoto, 1951, p. 6).

Com o objetivo de consolidar uma estrutura mais apropriada para o funcionamento de escolas normais e também solucionar o problema de vagas em âmbito de ensino secundário, a secretaria de educação propôs que houvesse uma separação em prédios dos institutos de 
educação e liceus, que funcionavam sob a mesma direção e num mesmo local. Com base na lei estadual 2.146, de 12 de maio de 1954, os institutos de educação passaram a funcionar nos prédios dos Grupos Escolares Getúlio Vargas e Saldanha da Gama (Relatório apresentado pelo Secretário José de Moura e Silva ao Governador Amaral Peixoto, 1954, p. 10).

Com essa medida, a oferta de ensino secundário pôde ser ampliada nos dois liceus, posto que as salas que anteriormente eram ocupadas pelas alunas do curso Normal ficaram vagas. Segundo Abreu (1955), com essa medida, o número de alunos matriculados no ensino secundário aumentou de 2.045, em 1951, para 2.672, em 1954.

Mesmo investindo nessa iniciativa para ampliar a oferta de matrículas gratuitas em termos da escola ginasial, a deficiência de vagas era visível, o que levou o governo estadual a conceder dotações orçamentárias aos ginásios da Campanha Nacional de Educandários Gratuitos (CNEG). O artigo 145 da Constituição Estadual de 1947 deixava claro que, nos municípios onde não houvesse ginásios, o Estado deveria custear a manutenção desses cursos.

Em consequência dessa determinação, o poder público julgou oportuno transferir verbas para os ginásios da Campanha Nacional de Educandários Gratuitos. Holanda (1997) informa que a CNEG utilizava os recursos da comunidade onde se instalava, mas também contava com auxílio financeiro do próprio Estado, em seus níveis federal, estadual e municipal, conforme citação abaixo:

Está sendo estudada a situação de alguns Cursos Especiais ${ }^{10}$ de Ensino Secundário, previstos pelo Artigo 145 da Constituição Estadual, o que levará, possivelmente, à conclusão de substituí-los por Ginásios da Campanha Nacional de Educandários Gratuitos, enquanto não é possível ao Estado instalar mais ginásios por sua conta; transferindo-se para estes, a verba prevista para os atuais Cursos Especiais, de eficiência muito reduzida (Relatório apresentado pelo Secretário de Educação José de Moura e Silva ao Governador Amaral Peixoto, 1951 p. 7).

Por outro lado, o governo adotou uma orientação que privilegiava a gratuidade de ensino, ainda que concedendo bolsas de estudo em escolas particulares. Nesse sentido, ao final do governo de Miguel Couto Filho havia sete ginásios públicos em todo o estado do Rio de Janeiro, como consequência da ampliação do número de ginásios oficiais.

No ano de 1955, o governo estadual criou três ginásios públicos nos municípios de Itaperuna, Barra Mansa e Teresópolis e, posteriormente, autorizou o funcionamento de mais um ginásio estadual nas instalações do Grupo Escolar Adino Xavier, no bairro de Alcântara.

${ }^{10}$ Os Cursos Especiais de Ensino Secundário foram criados pelo governo estadual desde a $2^{\mathrm{a}}$ metade dos anos de 1940 e funcionavam nos municípios de Carmo, São João da Barra, Parati, Santa Maria Madalena e Duas Barras. A frequência a esses cursos era baixa, tendo em vista que os mesmos atendiam a uma clientela com mais de dezessete anos, já adequando-se para atuar em atividade profissional. 
Além dessas medidas, em junho de 1957, autorizou o funcionamento de classes em período noturno, no prédio do Liceu de Humanidades, em Campos, e, em 1958, um curso ginasial no Instituto de Educação de Niterói.

Como ainda eram poucos os estabelecimentos públicos de ensino, Miguel Couto Filho, assim como seu antecessor, adotou uma política de incentivo ao desenvolvimento dos ginásios da Campanha Nacional de Educandários Gratuitos, como forma de responder à demanda por escola secundária existente naquele momento.

A oferta de ensino secundário por parte do estado não se limitou aos estabelecimentos públicos de ensino. Além de oferecer vagas em estabelecimentos oficiais, também adotou medidas que ampliavam essa oferta em estabelecimentos particulares, através da concessão de bolsas de estudos para alunos matriculados em escolas particulares. Como iniciativa alternativa, destinou-se apoio financeiro aos ginásios da Campanha Nacional de Educandários Gratuitos, em todo o território fluminense (BEZERRA, 1995).

\section{Considerações finais}

A escola, além de ser uma instituição de âmbito social, é um estabelecimento indiscutível de cultura, se colocando num patamar indiscutível de circulação da mesma. Os estudos históricos têm contribuído para avanços significativos na compreensão da dimensão escolar nas diversas épocas.

O papel da escolarização secundária é compreender o lugar social da formação acadêmica, humanista e propedêutica voltada para a transmissão de um repertório de cultura geral, confrontada com a dimensão de uma cultura técnica e profissionalizante.

O termo ensino secundário foi utilizado em vários contextos nos últimos séculos, fazendo com que os pesquisadores se colocassem numa posição mais atenta com relação à evolução semântica utilizada para esse termo. O adjetivo secundário surgiu a partir dos debates educacionais provocados com a Revolução francesa por volta de 1840 , tendo um sentido duplo: o grau intermediário entre o primário e o superior e o de se destinar à formação das classes abastadas.

O termo 'educação secundária' foi utilizado no Brasil a partir da criação do Colégio Pedro II em 1837, e estava vinculado à formação das elites para ter acesso ao ensino superior. Castro (2019), na obra Ensino Secundário no Brasil perspectivas históricas, esclarece que ensino secundário constitui um termo genérico para abarcar múltiplas possibilidades de 
formação: liceus, ateneus, ginásios, colégios, escolas técnicas e profissionalizantes nos grandes centros e no interior distante e desabitado do Brasil (CASTRO, 2019, p. 15).

As transformações que foram trazidas pela Revolução de 1930 implicaram na criação de órgãos administrativos que tinham como propósito preparar o país para as novas exigências de mercado. Dentre esses órgãos, destacamos o Ministério da Educação, cujo primeiro ocupante foi o Ministro Francisco Campos, que reformou o ensino secundário e superior. Tal reforma representou um momento de grande efervescência no setor educacional, uma vez que a educação até então oferecida tinha uma perspectiva clássica, que direcionava os estudantes para ingressarem no ensino superior, o que não se comportava mais nesse novo Brasil.

Naquele contexto, surge o Manifesto dos Pioneiros da Educação Nova, como resposta ao novo cenário político e educacional, que redesenhava o país. Dessa maneira, o presente texto visou recompor o processo histórico de implementação do ensino secundário no Brasil, destacando a importância das décadas de 1930, 1940 e 1950. Por outro lado, assinala também as possíveis contradições observadas na oferta de ensino do Estado e da iniciativa privada.

\section{REFERÊNCIAS}

ABREU, J. O sistema educacional fluminense: uma tentativa de interpretação e crítica. Rio de Janeiro, RJ: MEC/INEP/CILEME, 1955. n. 6.

BEISIEGEL, C. R. Ação política e expansão da rede escolar: os interesses do deputado estadual e a democratização do ensino secundário no Estado de São Paulo. In: A qualidade do ensino na escola pública. Brasília, DF: Liber Livro, 1964. p. 15-95.

BEISIEGEL, C. R. Ensino público e educação popular. In: PAIVA, V. (Org.). Perspectivas e dilemas da educação popular. Rio de Janeiro, RJ: Ed. Graal, 1986. p. 63-83.

BEZERRA, M. C. C. O ensino secundário no antigo estado do Rio de Janeiro: a inibição dos ginásios públicos e a expansão dos ginásios da CNEG. 1995. Dissertação. (Mestrado em Educação) - Faculdade de Educação, Universidade Federal Fluminense, Niterói, RJ, 1995.

BRANDÃO, A. A. P. Executivo estadual e políticas públicas no antigo Estado do Rio de Janeiro (1950-1954): um estudo do segundo governo Amaral Peixoto. 1992. Dissertação. (Mestrado em Sociologia e Antropologia) - Universidade Federal do Rio de Janeiro, Rio de Janeiro, RJ, 1992.

BRASIL. Constituição (1934). Título V. Capítulo II. Disponível em: http://www.planalto.gov.br/ccivil_03/Constituicao/Constitui\%C3\%A7ao34.htm. Acesso em: 10 janeiro 2020.

BRASIL. Constituição (1937). Sessão "Da Educação e da Cultura", art.129. Constituição dos Estados Unidos do Brasil. Rio de Janeiro, RJ, 1937. Disponível em: 
http://www.planalto.gov.br/ccivil_03/Constituicao/Constitui\%C3\%A7ao37.htm. Acesso em: 10 janeiro 2020.

BRASIL. Decreto-lei n. 19.402 de 14 de novembro de 1930. Cria uma Secretária de Estado com a denominação de Ministério dos Negócios da Educação e Saúde Pública. Rio de Janeiro, RJ, 18 nov. 1930. Disponível em:

http://www2.camara.leg.br/legin/fed/decret/1930-1939/decreto-19402-14-novembro-1930515729-publicacaooriginal-1-pe.html. Acesso em: 06 mar. 2020.

BRASIL. Decreto-Lei n. 6.141 de 28 de dezembro de 1943. Definiu o ensino comercial em todo país e foi denominada Lei Orgânica do Ensino Comercial. Rio de Janeiro, RJ, 31 dez. 1943. Disponível em: https://www2.camara.leg.br/legin/fed/declei/1940-1949/decreto-lei6141-28-dezembro-1943-416183-publicacaooriginal-1-pe.html. Acesso em: 10 mar. 2020.

BRASIL. Lei n. 4.024 de 20 de dezembro de 1961. Fixa as Diretrizes e Bases da Educação Nacional. Brasília, DF, 27 dez. 1961. Disponível em: https://www2.camara.leg.br/legin/fed/lei/1960-1969/lei-4024-20-dezembro-1961-353722publicacaooriginal-1-pl.html. Acesso em: 10 mar. 2020.

CARR, E. H. Que é história? 3. ed. Rio de Janeiro, RJ: Paz e Terra, 1982.

CASTRO, C. A. (Org.). Ensino secundário no Brasil: perspectivas históricas. São Luís do Maranhão: EDUFMA, 2019.

CUNHA, L. A. A política educacional e a formação da força de trabalho industrial na era Vargas. In: A Revolução de 30. Rio de Janeiro, RJ: Editora Universidade de Brasília, 1983 (Coleção Temas Brasileiros, 54)

CUNHA, L. A. Educação, estado e democracia no Brasil. São Paulo, SP: Cortez; Niterói: Editora da Universidade Federal Fluminense; Brasília: FLACSO do Brasil, 1991.

FIALHO, L. M. F.; FREIRE, V. C. C. Educação formativa de uma líder política cearense: Maria Luiza Fontenele (1950-1965). Cadernos de História da Educação, Uberlândia (MG), v. 17, p. 343, 2018. Disponível em: http://www.seer.ufu.br/index.php/che/article/view/43290. Acesso em: 10 mar. 2020.

FIALHO, L. M. F.; SÁ, E. C. V. Educadora Henriqueta Galeno: a biografia de uma literata e feminista (1887- 1964). História da Educação, v. 22, p. 169-188, 2018. Disponível em: https://seer.ufrgs.br/asphe/article/view/75182. Acesso em: 10 mar. 2020.

FIALHO, L. M. F.; SOUSA, F. G. A. de. Irmã Elisabeth Silveira e a educação feminina no Colégio da Imaculada Conceição, Fortaleza-CE. Revista Diálogo Educacional, Curitiba (PR), v. 21, n. 68, 2021. Disponível em:

https://periodicos.pucpr.br/index.php/dialogoeducacional/article/view/27388. Acesso em: 10 mar. 2020.

FRANCO, M. A. C. O trabalho como princípio educativo: uma investigação teóricometodológica (1930 - 1960). 1990. Tese. (Doutorado em Educação) - Departamento de Educação, Pontifícia Universidade Católica do Rio de Janeiro, Rio de Janeiro, RJ, 1990. 
HOLANDA, I. C. Campanha Nacional de Escolas da Comunidade. 1997. Dissertação (Mestrado em Educação) - Escola de Ciências Sociais, Fundação Getúlio Vargas, Rio de Janeiro, RJ, 1997.

LOPES, A. P. C. Legislação e processos educativos: A constituição da escola primária no Piauí (1845 a 1889). Educação \& Formação, Fortaleza (CE), v. 4, n. 1, p. 50-65, 2019. Disponível em: https://revistas.uece.br/index.php/redufor/article/view/866. Acesso em: 10 mar. 2020.

MORAES, M. C. M. Reformas de ensino, modernização administrada: a experiência de Francisco Campos - anos vinte e trinta. Centro de Ciências da Educação. Florianópolis, SC: Núcleo de Publicações, UFSC, 2000.

NASCIMENTO, G.; MACHADO, C. J.; ALMEIDA, A. Escritos e representações de Jandira Pinto: a reformuladora de Pindobal na Paraíba do século XX. Práticas Educativas, Memórias e Oralidades - Rev. Pemo, Fortaleza (CE), v. 3, n. 1, e313816, 2020. Disponível em: https://revistas.uece.br/index.php/revpemo/article/view/3816. Acesso em: 10 mar. 2020.

NASCIMENTO, J. C. O contexto de expansão do ensino secundário e a história do Ginásio Brigadeiro Newton Braga. In: JORNADA DO HISTEDBR, 9., 2013, Cascavel. Anais [...]. Cascavel, PR: Universidade Estadual do oeste do Paraná. 2013.

NUNES, C. Escola \& dependência: o ensino secundário e a manutenção da ordem. Rio de Janeiro, RJ: Achiamé, 1980.

NUNES, C. O velho e o bom ensino secundário: momentos decisivos. Revista Brasileira de Educação, Rio de Janeiro, n. 14, p. 35-60, maio/jun./ago. 2000.

NUNES, M. T. Ensino Secundário e Sociedade Brasileira. 2. ed. São Cristóvão, SE: Editora da UFS, 1999.

PALMA FILHO, J. C. (Org.) A Educação Brasileira no período de 1930 a 1960: a Era Vargas. Pedagogia Cidadã. Cadernos de Formação. História da Educação. 3. ed. São Paulo, SP: PROGRAD/UNESP, Santa Clara Editora, 2005. p. 61-74.

SAVIANI, D. Aberturas para a História da Educação: do debate teórico-metodológico no campo da história ao debate sobre a construção do sistema nacional de educação no Brasil. Campinas, SP: Autores Associados, 2013.

SILVA, G. B. A educação secundária: perspectiva histórica e teoria. São Paulo, SP: Companhia Editora Nacional, Atualidades pedagógicas, 1969. v. 94.

SPOSITO, M. P. O povo vai à escola: a luta popular pela expansão do ensino público em São Paulo. São Paulo, SP: Loyola, 1984. (Coleção Educação Popular, n. 2) 


\section{Como referenciar este artigo}

NASCIMENTO, J. C; FARIA, L. C. M. A expansão do ensino secundário no Brasil pós1930. Revista Ibero-Americana de Estudos em Educação, Araraquara, v. 16, n. esp. 3, p. 1455-1472, jun. 2021. e-ISSN: 1982-5587. https://doi.org/10.21723/riaee.v16iesp.3.15292

Submissão em: 05/02/2021

Revisões requeridas em: 30/03/2021

Aprovado em: $12 / 05 / 2021$

Publicado em: 01/06/2021 